\title{
Las cuatro grandes empresas comercializadoras y los precios internacionales de los alimentos
}

The four major trading companies and international food prices

Luis Gómez Oliver *

Rosario Granados Sánchez **

\section{Resumen}

Una gran parte de los mercados agroalimentarios son de ámbito local o regional; pero, en situaciones de escasez, el mercado internacional es el que mueve el precio en el margen e impacta de manera directa en los mercados nacionales.

Cuatro grandes comercializadoras de granos alimenticios: Archer Daniels Midland (ADM), Bunge, Cargill y Louis Dreyfus, (llamadas las ABCD), controlan la mayor parte del comercio internacional de cereales y granos, y tienen gran influencia sobre la determinación de los precios internacionales de los alimentos. Con más de un siglo de antigüedad, constituyen un grupo de empresas sumamente peculiar. De actitud discreta, han cambiado muy poco en su larga existencia. Se ubican entre las más grandes compañías a nivel mundial, pero son empresas tradicionalmente familiares. Además de las actividades de comercio, transporte y almacenamiento de granos, participan de manera importante en el financiamiento de la producción, a través de la entrega de paquetes tecnológicos e insumos (semillas, fertilizantes y agroquímicos); sus empresas subsidiarias en numerosos países consumen gran parte de las materias primas que comercializan, de manera que sus precios son más bien precios de transferencia; almacenan en instalaciones propias; transportan en sus propios ferrocarriles y barcos; son productores ganaderos y avícolas; tienen gran importancia en la producción de alimentos para animales y en los mercados de biocombustibles; son propietarias o arrendatarias de tierras; y son entidades financieras que participan activamente en los mercados de derivados.
* Doctor en Economía. Profesor titular de tiempo completo en la Facultad de Economía de la UNAM. Durante 28 años fue funcionario internacional en la ONU, colaborando en la CEPAL y en la FAO. También se ha desempeñado como consultor en el Banco Mundial, en la FAO y en otras instituciones internacionales. lgomezoliver8@yahoo.com.mx

** Maestra en Estrategia Agroempresarial. Profesor adjunto en la Facultad de Economía de la UNAM. Consultor en la Organización de Naciones Unidas para la Alimentación y la Agricultura, Agroanálisis A.C. y la Facultad de Economía de la UNAM. rosariogs_86@hotmail.com

\section{Palabras clave}

Producción y organización, Agricultura y comercio, Empresas productivas

Keywords

Production and Organization, Agriculture in International trade, Productive Enterprises

JEL $D 2, Q 17, P 42$ 
Luis Gómez Oliver | Rosario Granados Sánchez |

Las cuatro grandes empresas comercializadoras y los precios internacionales de los alimentos

\section{Abstract}

A large part of the food markets are local or regional; but in situations of production shortages, the international market is what moves the price at the margin and impacts directly on national markets.

Four major traders of food grains: Archer Daniels Midland (ADM), Bunge, Cargill and Louis Dreyfus, (called the $A B C D$ ), control most of the international trade in cereals and grains, and have great influence on determining international prices food. More than a century old, they constitute a most peculiar group of companies. With a low profile, they have changed very little in its long existence. They are among the largest companies worldwide, but are traditionally family-owned firms. In addition to trading, transport and storage activities, they participate in the financing of agricultural production, through the delivery of technology packages and inputs (seeds, fertilizers and agrochemicals); their subsidiaries in numerous countries consume most of the commodities they sell, so their prices are rather transfer prices. They use their own trains and ships to transport the grains; storage is made in their own storage facilities. They are livestock and poultry producers, have great importance in the production of animal feed and biofuel markets; and are owners or lessees of land. They are also financial institutions active in the derivatives markets.

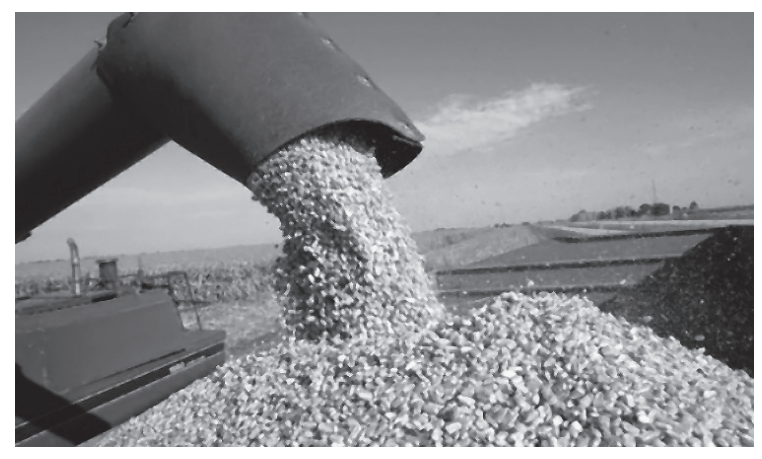

\section{Introducción}

Los precios internacionales de los alimentos tienen una incidencia significativa sobre variables económicas y sociales fundamentales tanto por el impacto directo en las facturas del comercio internacional como, principalmente, por su influencia en los costos de los alimentos para la población.

No se trata de una determinación simple de los precios internacionales sobre los precios de los alimentos en cada país; una gran parte de los mercados agroalimentarios son nacionales o de ámbito regional o local. La baja densidad económica de la mayor parte de los productos alimenticios y su carácter perecedero implican altos costos de transporte y favorecen un abastecimiento interno. Hay muchos alimentos que no son objeto de comercio internacional o incluso algunos pueden ser prácticamente desconocidos fuera de su país de origen. Los países (o amplias regiones en los mismos) tienden a mantener hábitos de consumo relacionados con la disponibilidad local de alimentos, concentrando su consumo básico en un cereal principal, complementado por variados productos del entorno propio. En general, la producción nacional cubre la mayor proporción del consumo de alimentos básicos de consumo generalizado en la dieta, principalmente, cereales, hortalizas, leche y carnes. Otros productos que se originan en cultivos con hábitats más restringidos, particularmente cultivos tropicales, como azúcar, varios aceites vegetales, café, cacao, té y varios tipos de frutas, sí son importados en gran proporción por un buen número de países. 


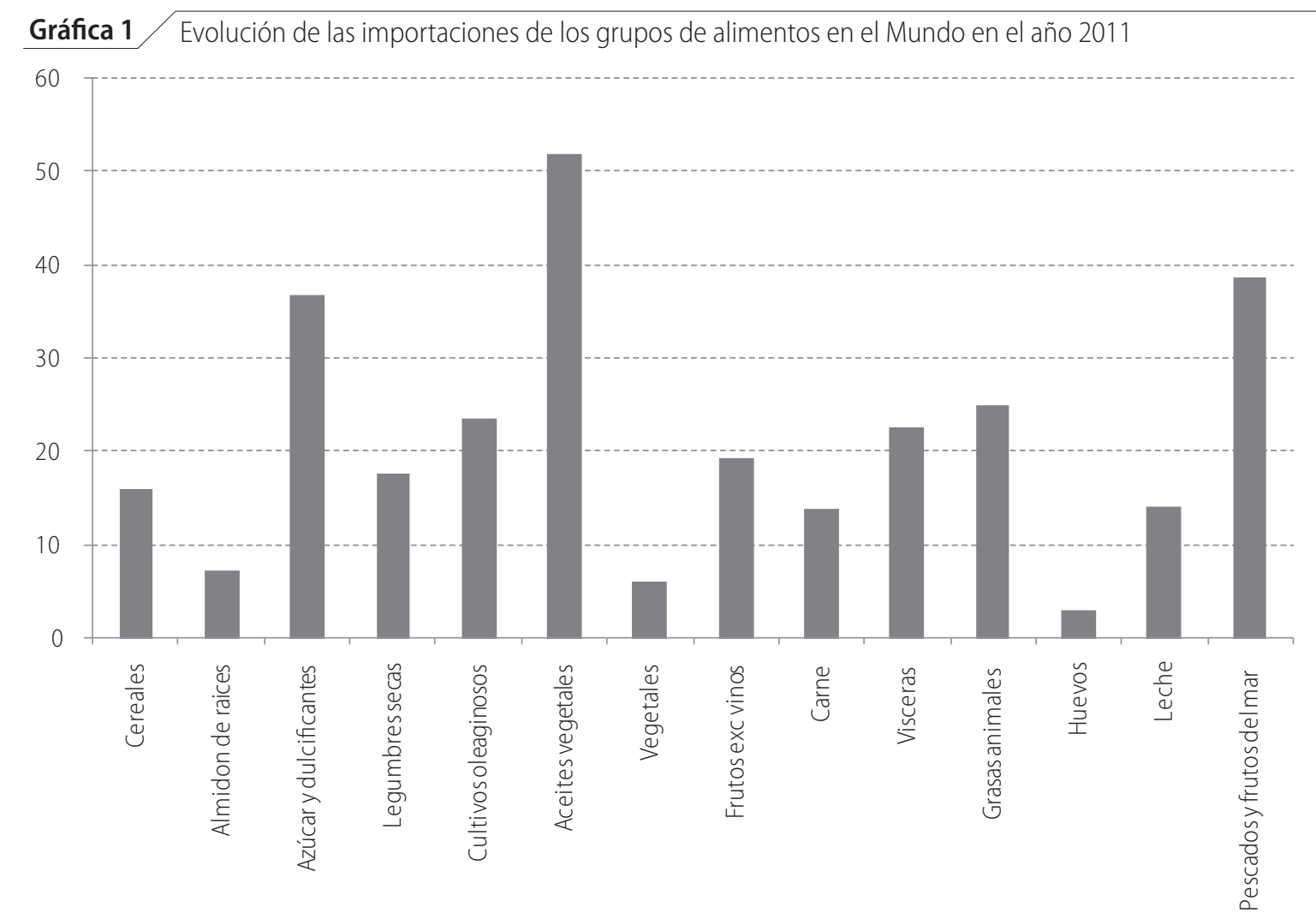

Fuente: elaboración propia con datos de FAOSTAT, 2015.

Sin embargo, el mercado internacional es el que mueve el precio en el margen. En casos de escasez, el alza de los precios internacionales eleva el precio de equilibrio en los mercados locales, a través del mayor precio de las importaciones. A menos de que haya políticas específicas para evitarlo, el precio interno se alinearía al nivel del precio del producto importado. Aunque la participación de las importaciones sea minoritaria en la oferta total, el precio internacional se reflejaría en el mercado nacional.

\section{Crisis alimentarias}

En los últimos diez años se han vivido dos episodios de alza de precios internacionales de los alimentos. Entre agosto de 2006 y abril de 2008 los precios de los alimentos crecieron $70.9 \%$.
Los precios de los cereales se duplicaron sobradamente, aumentando 128.7\%; en particular, el precio internacional del arroz aumentó $168.5 \%$, el del maíz $117.9 \%$ y el del trigo $90.0 \%$. También el precio de los aceites aumentó a más del doble, $130.4 \%$, y el de los lácteos casi se duplicó, $96.6 \%$ (ver cuadro 1 y gráfica 2 ).

Se presentaron riesgos de hambrunas en 22 países y en una treintena de países se generaron fuertes riesgos de inestabilidad social1 en varias grandes ciudades hubo saqueos y desórdenes. El costo humano, social y económico fue enorme. El Banco Mundial estimó que 105 millones de personas cayeron en la pobre-

1 Conferencia de alto nivel sobre la seguridad alimentaria mundial: Los desafíos del cambio climático y la bioenergía, Roma, FAO, 2008, p. 17. 
Luis Gómez Oliver | Rosario Granados Sánchez |

Las cuatro grandes empresas comercializadoras y los precios internacionales de los alimentos

Cuadro 1

Principales periodos de alza en el índice de precios internacionales de los alimentos (Variación porcentual).

\begin{tabular}{llllll}
\hline \multicolumn{1}{c}{ Producto } & \multicolumn{1}{c}{$\begin{array}{c}\text { Ags } 1990-\text { Ags } \\
2006\end{array}$} & $\begin{array}{c}\text { Ago } 2006-\text { Abr } \\
2008\end{array}$ & $\begin{array}{c}\text { Jun } 2010-\text { Feb } \\
2011\end{array}$ & $\begin{array}{r}\text { Feb } 2011-\text { Jul } \\
2015\end{array}$ & $\begin{array}{c}\text { Ags } 2006-\text { Jul } \\
2015\end{array}$ \\
\hline Alimentos & 17.01 & 70.91 & 41.04 & -31.43 & 29.42 \\
Carnes & 13.66 & 20.25 & 10.84 & 0.09 & 36.43 \\
Lácteos & 33.21 & 96.56 & 15.79 & -37.88 & 18.71 \\
Cereales & 8.6 & 128.7 & 71.57 & -34.6 & 44.03 \\
Aceites & 61.02 & 130.41 & 66.79 & -48.48 & 25.5 \\
Azúcar & -5.27 & -6.63 & 85.91 & -56.67 & -5.06 \\
Trigo & & 90.3 & 84.93 & -34.39 & 18.39 \\
Arroz & & 168.5 & 16.09 & -27.59 & 26.33 \\
Maíz & & 117.88 & 76.13 & -37.74 & 57.57
\end{tabular}

Nota: Cálculo realizado con precios nominales.

Fuente: elaboración propia con datos de FAO GIEWs, 2015.

za, lo que a juicio de esta institución significó un retroceso de siete años en el combate a la pobreza. $^{2}$

En 2007 los Países de Bajos Ingresos Deficitarios en Alimentos (PBIDA) ${ }^{3}$ tuvieron que pagar 120 mil millones de dólares por concepto de importaciones de alimentos, lo que representó un aumento de 35\% respecto de 2006. En 2008 su factura por importación de alimentos llegó a 169 mil millones de dólares, es decir, $40 \%$ de aumento adicional, lo que significó una pesada carga en la balanza comercial de estos países pobres. ${ }^{4}$ Para 33 países importadores netos de alimentos el incremento en los

2 Burns, A. and E. Riordan, Global Economic Prospects, Volume 3, Washington D.C., World Bank, 2011, Pág.3.

3 Los Países de Bajos Ingresos Deficitarios en Alimentos (PBIDA) son 55 países deficitarios de alimentos con un ingreso anual per cápita inferior al nivel utilizado por el Banco Mundial para determinar el derecho a recibir la asistencia de la AIF (es decir, USD 1945 en 2011).

4 Perspectivas alimentaria. Análisis del mercado mundial, Roma, FAO, 2008, p. 1. precios implicó un costo de 2300 millones de dólares entre enero de 2007 y junio de 2008, es decir, $0.5 \%$ de su PIB. ${ }^{5}$

El valor de las importaciones de alimentos de 2008 respecto de 2007 representó un aumento de $35 \%$ en los países en desarrollo y de $18 \%$ en los países desarrollados. ${ }^{6} \mathrm{El}$ alza de los precios de los alimentos fue la primera causa de presiones inflacionarias en numerosos países. ${ }^{7}$ La tarifa por importaciones significó una fuerte presión en las cuentas externas de numerosos países, principalmente en los países PBIDA.

5 Burns, A. and E. Riordan, Global Economic Prospects, Volume 3, Washington D.C., World Bank, 2011, p. 3.

6 Gómez Oliver, Luis, Conferencia magistral: Desarrollo del sector agropecuario en el marco de la sustentabilidad y la seguridad alimentaria, IIEC de la UNAM, México, 2013, p. 20.

7 En México, a pesar de las políticas de protección al consumidor y los subsidios a las cadenas productivas, el incremento en los precios de los alimentos explica más de la mitad (54.1\%) de la inflación global acumulada entre agosto 2006 y febrero 2008. Entre junio 2010 y febrero 2012, la participación de las alzas en los precios de los alimentos en la inflación global acumulada en ese periodo fue de $49.3 \%$. Estimaciones propias con información estadística de INEGI, 2015. 
Una segunda crisis alimentaria mundial se presentó entre junio de 2010 y febrero de 2011. En apenas ocho meses los precios de los alimentos aumentaron $41 \%$. En ese corto periodo 44 millones de personas cayeron en la pobreza: 34 millones, en países de ingreso medio y 10 millones en países de bajo ingreso. ${ }^{8}$

Las crisis por la escasez de alimentos y por la abrupta alza de precios fueron sumamente graves. Incluso, esta alza de precios fue uno de los principales detonantes de las revueltas y protestas sociales masivas que dieron origen a la "primavera árabe", movimiento que habría de cambiar los regímenes de gobierno de varios países del norte de África y que aún actualmente tiene consecuencias de primera magnitud.

8 Food Price Watch, Washington D.C., World Bank, 2011, p. 1.
Los impactos de las alzas en los precios internacionales de los alimentos son mayores en los países en desarrollo, en los cuales estos productos representan entre 30 y 40\% del consumo; en cambio, en los países de alto ingreso solamente representan 16\%..$^{9}$ Así, cada 1\% de aumento en el índice de precios internos de los alimentos en los países desarrollados implica $0.16 \%$ de incremento en la inflación; en cambio, la incidencia en la inflación en los países en desarrollo sería significativamente mayor, entre 0.30 y $0.40 \%$.

9 Gómez Oliver, Luis, Conferencia magistral: Desarrollo del sector agropecuario en el marco de la sustentabilidad y la seguridad alimentaria, IIEC de la UNAM, México, 2013, p. 19. El FMI estima que para 120 países en desarrollo, el consumo de alimentos representa $37 \%$ del consumo total, lo que significaría que por cada $1 \%$ de aumento en el índice de precios de los alimentos la inflación crece $0.37 \%$. (Food and Fuel Prices-Recent Developments, Macroeconomic Impact, and Policy Responses, Washington. D.C., IMF, 2008, p. 19).

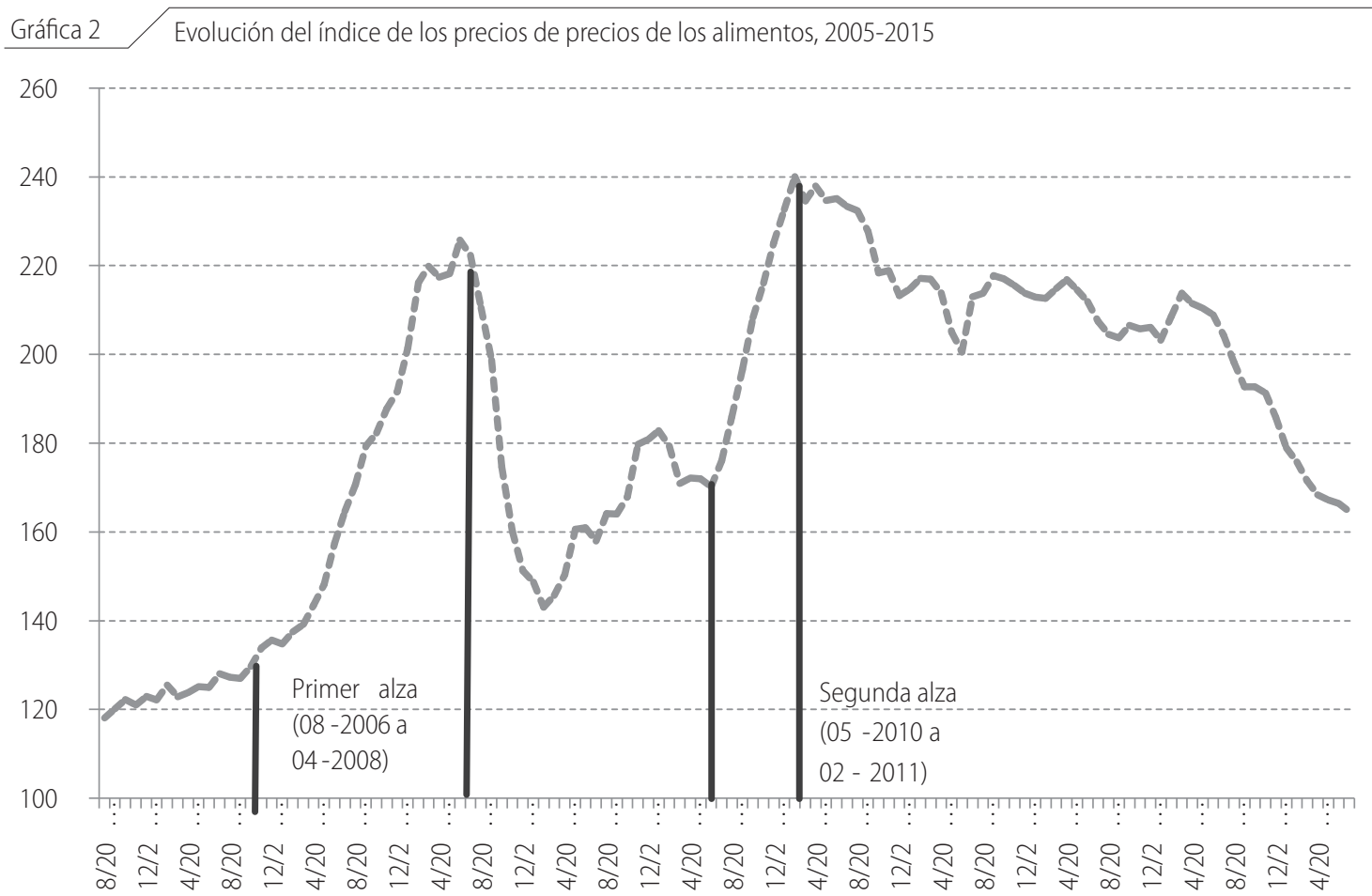

Fuente: elaboración propia con datos de FAOSTAT, 2015. 
Análogamente, el impacto sobre la población pobre que dedica hasta más de $50 \%$ de su ingreso a la compra de alimentos es mucho más grave que en la población más solvente donde representa entre 5 y $15 \%$ del gasto familiar.

Estas abruptas y significativas alzas en los precios de los alimentos en el último decenio contrastan con la evolución de largo plazo. Hasta el año 2000 los precios de los alimentos se habían mantenido bajos de una manera relativamente estable, incluso, en términos reales los precios de los alimentos disminuían sostenidamente. La tendencia a la baja en términos reales se mantuvo por varias décadas, salvo en los años excepcionales de 1973 a 1975, cuando a una serie de factores que redujeron la producción mundial, se sumó la masiva importación de trigo de la URSS, China y varios países de
Europa Oriental, provocando una súbita alza en los precios del trigo y de otros cereales durante un breve lapso.

En términos generales, durante toda la segunda mitad del siglo pasado la preocupación respecto de los precios de los productos agroalimenticios era en el sentido de impedir su baja. Se consideraba que el principal problema que debía enfrentar la agricultura era el lento crecimiento de la demanda respecto de una amplia capacidad potencial para aumentar la producción. Los países desarrollados establecieron programas para limitar las siembras y para financiar la exportación subsidiada de excedentes, a fin de evitar que los bajos precios significaran menores remuneraciones a los agricultores, que desalentaran la producción y se redujera el ingreso de la población rural. El abastecimiento de alimentos baratos parecía

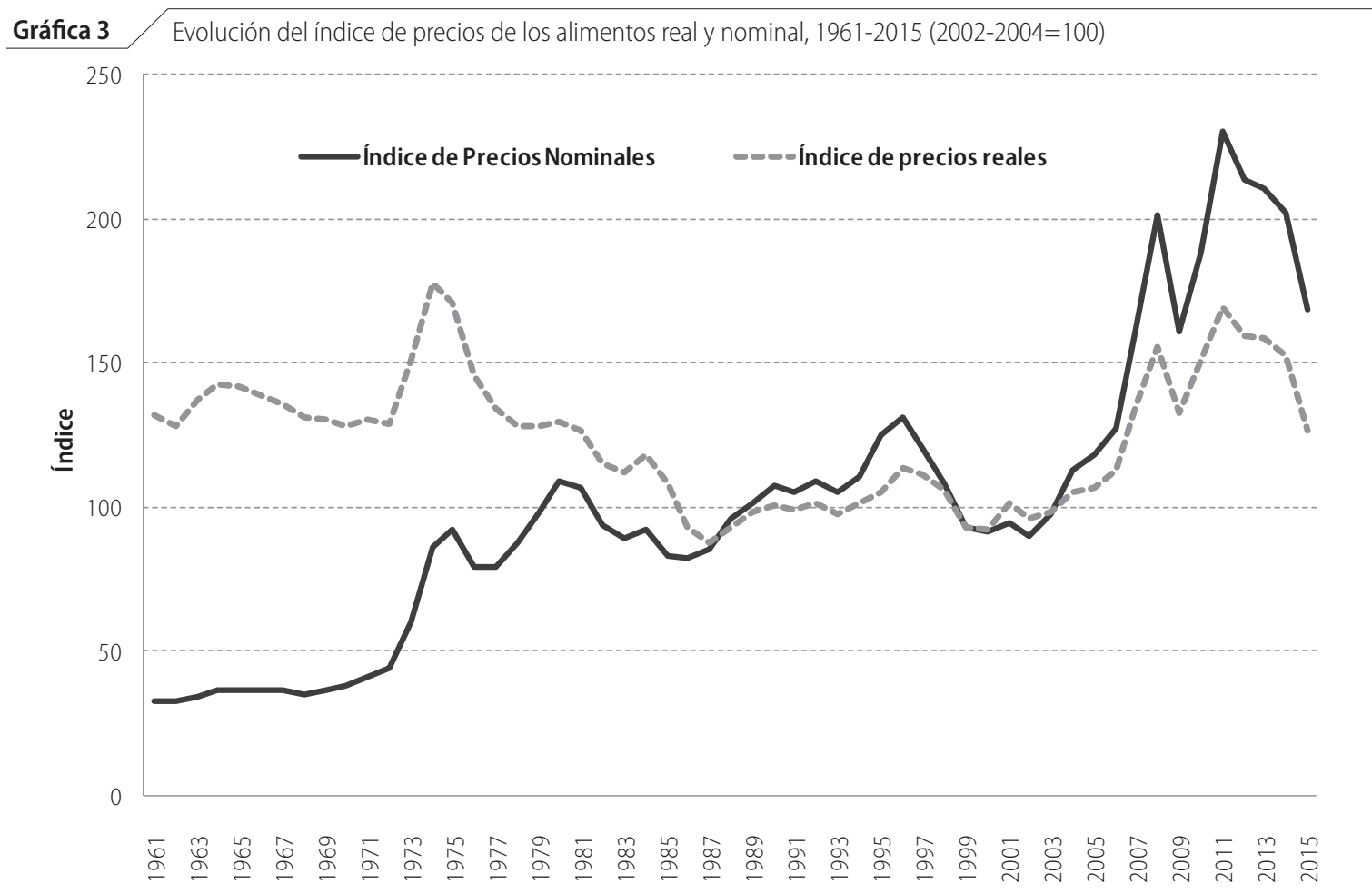

Fuente: elaboración propia con datos de FAOSTAT, 2015. 


\section{BË̂̀NGE}

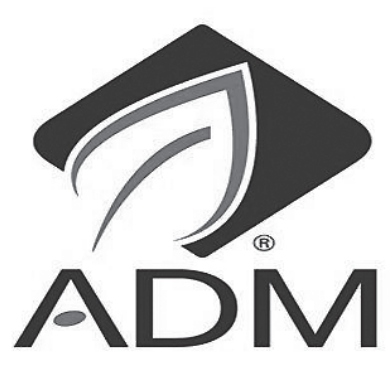

asegurado; una gran parte de los países juzgaba innecesario fortalecer la inversión productiva en la agricultura.

En ese escenario, el acelerado crecimiento económico alcanzado en la primera década del presente siglo por algunos países en desarrollo, como China, India o Brasil, implicó importantes cambios en la dieta de poblaciones muy amplias, con incrementos en el consumo de aceites y de alimentos de origen animal, lo que significó fuertes aumentos en la demanda de oleaginosas, así como de cereales y pasta de soya para su transformación en carne, leche o huevos; por cada kilogramo de estos productos deben destinarse a la alimentación animal entre 2 y 12 kilogramos de productos vegetales, dependiendo del producto pecuario y de la tecnología.

Estos incrementos en el consumo se han dado a lo largo del tiempo y, por sí mismos, no podrían explicar la brusca elevación de los precios en 2006-2008 o 2010-2011; sin embargo, sí contribuyeron de manera muy importante, junto con la subinversión en agricultura y el lento crecimiento de la producción agrícola, a un desbalance en el ritmo de progreso de la producción respecto del crecimiento del consumo, a la continua disminución de las reservas y al aumento de la vulnerabilidad ante fenómenos extremos que afectan cada vez más frecuentemente a la producción agrícola, como consecuencia del cambio climático.

La crisis alimentaria coincidió y se vinculó con la crisis energética que llevó los precios del petróleo a más de cien dólares por barril, así como con la crisis económica derivada de la crisis financiera.

- A consecuencia de los aumentos en el precio del petróleo, también subieron los precios de los insumos para la producción agrícola (gasolina y diesel para maquinaria y equipos, fertilizantes, agroquímicos y plásticos para empaque); este aumento de costos implicó una mayor presión para el alza de los precios de los alimentos.

- Los precios al consumidor se incrementaron adicionalmente por las alzas en los costos de transporte derivados de los elevados precios que mantuvo el petróleo hasta fines de 2014.

- Se presentó un incremento en la producción de biocombustibles en Estados Unidos y Europa. En particular, Estados Unidos, primer productor y exportador mundial de maíz, destinó cerca de 100 millones de toneladas, una tercera parte del total de su producción, a la fabricación de etanol, al mismo tiempo, redujo sus exportaciones del cereal.

- A esas causas se sumó la reacción de los países exportadores que redujeron significativamente la oferta en los mercados internacionales, a fin de asegurar el abasto interno y reducir el impacto del alza de precios de los alimentos sobre sus poblaciones. Al menos 15 países, incluyendo varios de los principales productores, impusieron restricciones a las exportaciones. ${ }^{10} \mathrm{En}$ el caso

10 Braun, J. y Ahmed, A., High Food Prices: The What, Who, and How of Proposed Policy Actions, Washington. D.C., International Food Policy Research Institute, IFPRI, 2008, p. 5. 
Luis Gómez Oliver | Rosario Granados Sánchez |

Las cuatro grandes empresas comercializadoras y los precios internacionales de los alimentos

del arroz, las compras de pánico de varios países asiáticos elevaron explosivamente el precio del cereal.

- Las fuertes turbulencias bursátiles, derivadas de la crisis subprime y sus consecuencias sobre el conjunto del sector financiero, la disminución de las tasas reales de interés y la incertidumbre sobre la evolución futura de los tipos de cambio, motivaron una fuerte emigración de capitales hacia las materias primas, incluyendo los productos básicos agropecuarios, provocando una fuerte volatilidad en los precios de los alimentos.

Las cuatro grandes empresas comercializadoras (ABCD) y los precios internacionales de los alimentos

La amplitud, diversidad y profundidad que pueden alcanzar los impactos de los precios de los alimentos sobre aspectos cruciales de la economía hacen relevante el análisis de sus determinantes. En principio, la existencia de un gran número de productores y de consumidores podría hacer suponer que los precios de los alimentos obedecen a las variables que determinan la oferta y la demanda a través de los mecanismos de libre competencia. Sin embargo, la dispersión y reducida escala tanto de los productores primarios como de los consumidores finales se ve acompañada por la participación de varios tipos de agentes intermediarios con diversos grados de influencia en la formación de los precios.

Las grandes empresas comercializadoras de granos, las empresas proveedoras de semillas e insumos, las industrias elaboradoras de alimentos, y las cadenas internacionales de distribución y supermercados ejercen un importante grado de influencia en los niveles y las variaciones de los precios en los diferentes mer- cados de alimentos. De esta manera, el mercado de alimentos semejaría un reloj de arena, donde la conexión entre el gran número de productores primarios y la enorme población de consumidores finales se realiza a través de estrechos túneles de intermediación, transformación y comercio, donde la competencia está lejos de ser libre. ${ }^{11}$

La globalización, la bursatilización de las empresas mundiales y el dominio de la esfera financiera sobre la economía real han provocado que las diferencias entre los grandes corporativos mundiales de los diversos sectores productivos parezcan cada vez menores. Las modalidades organizativas y de gestión de las grandes firmas globales parecen cada vez más homogéneas e indistintas cualquiera que sea el sector productivo. Pero este no es el caso de las cuatro grandes comercializadoras de granos alimenticios que controlan la mayor parte del comercio internacional de cereales y granos. Se trata de un grupo sumamente peculiar que resulta excepcional entre los grandes conglomerados empresariales mundiales.

Las ABCD: Archer Daniels Midland (ADM), Bunge, Cargill y Louis Dreyfus, manejan la mayor parte del comercio mundial de cereales, comprando en grandes volúmenes a granel en origen. La actividad básica de las $A B C D$ se centra en la comercialización internacional de granos y materias primas, dominando los mercados de exportación de numerosos países, sobre todo en América. Sin embargo, su ámbito de actividad presenta una integración vertical rápidamente creciente. Además de las actividades de comercio, transporte y almacenamiento de granos, participan en el aprovisionamiento de insumos agrícolas,

11 Braun, J. D. Burch y J. Clapa, El lado oscuro del comercio mundial de cereales. El impacto de las cuatro grandes comercializadoras sobre la agricultura mundial, Londres, oxfam International, 2012, p. 12. 
como semillas, fertilizantes y agroquímicos; almacenan en instalaciones propias; transportan en sus propios ferrocarriles y barcos; producen alimentos para animales; son productores ganaderos y avícolas; son propietarias o arrendatarias de tierras; y son entidades financieras. Tienen ya una gran importancia en los mercados de biocombustibles, los cuales utilizan insumos de materias primas, en cuyos mercados estas empresas tienen fuerte incidencia, como en la soya, el maíz o el azúcar. Su proceso de integración vertical no se limita a las cadenas agroalimentarias; también incursionan en la elaboración de productos industriales; están participando crecientemente en la producción y comercialización de plásticos, tintes o almidones. Se ubican en el grupo de las grandes empresas a nivel mundial; pero son empresas tradicionalmente familiares (aunque ADB y Bunge cotizan en bolsa), no tienen marca que proteger y evitan el protagonismo. ${ }^{12}$

En las últimas décadas el sector agroalimentario ha experimentado profundas transformaciones, como la mayor integración vertical y el predominio de los supermercados, como Wal-Mart o Carrefour, sobre las cadenas de numerosos productos agroalimentarios; el surgimiento de empresas biotecnológicas proveedoras de insumos, como Monsanto, Syngenta o Ciba-Geigy; o las fusiones y adquisiciones entre las grandes procesadoras de alimentos. Sin embargo, en el comercio internacional de granos, dominado por las ABCD, los cambios han sido mínimos. Estas empresas, con más de un siglo de antigüedad (dentro de apenas tres años Bunge cumplirá 200 años de actividad ininterrumpida), son administradas por juntas directivas compuestas por

12 Braun, J. D. Burch y J. Clapa, El lado oscuro del comercio mundial de cereales. El impacto de las cuatro grandes comercializadoras sobre la agricultura mundial, Londres, OXFAM International, 2012, p. 4.
En las últimas agroalimentario ha experimentado profundas transformaciones, como la mayor integración vertical y el predominio de los supermercados, como Wal-Mart o Carrefour sobre las cadenas de numerosos productos agroalimentarios

miembros de una misma familia, unos pocos socios privados y algunos empleados, constituyendo un sector que ha cambiado muy poco desde el siglo XIX. La de más reciente creación es ADM, que se fundó en 1902, aunque su operación mundial data de los años setenta del siglo $\mathrm{xx}$, cuando eran cinco grandes empresas. Justamente, el otro cambio relevante en la casi inmovilidad de este universo, tecnológicamente muy dinámico pero de instituciones formales estáticas, fue la quiebra en 2002 de André, que tenía sede en Suiza. ${ }^{13}$

13 Braun, J. D. Burch y J. Clapa, El lado oscuro del comercio mundial de cereales. El impacto de las cuatro grandes comercializadoras sobre la agricultura mundial, Londres, OXFAM International, 2012, p. 8. 
La administración tradicional de estas empresas genera una gran opacidad sobre sus prácticas gerenciales, sobre todo en el caso de las que no cotizan en bolsa. Asimismo, su actitud discreta y el bajo perfil en los debates públicos sobre políticas que afectan los intereses de los productores o de los consumidores de alimentos, deja escaso conocimiento público sobre su incidencia en los mercados. Sin embargo, es evidente que su información de la coyuntura en el ámbito mundial y su enorme poder de mercado les dan indudables ventajas. Su influencia va más allá de las variaciones en los precios al productor. A través de su importante participación en el financiamiento de la producción, de la entrega de paquetes tecnológicos e insumos (semillas, fertilizantes y agroquímicos), del manejo de inventarios almacenados en instalaciones propias, o del transporte y comercialización en sus propios barcos y ferrocarriles, inciden en las condiciones de las cadenas de producción-consumo, desde la decisión de qué, cuánto y dónde producir hasta las condiciones de abastecimiento en los diversos los mercados de consumo final.

Sus subsidiarias consumen gran parte de las materias primas que comercializan, de manera que los precios de éstas pasan a ser más bien costos operativos internos o precios de

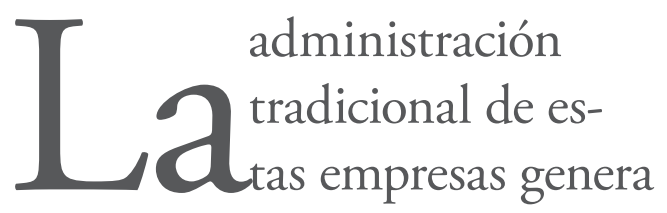
una gran opacidad sobre sus prácticas gerenciales, sobre todo en el caso de las que no cotizan en bolsa transferencia, aumentando su capacidad de influir en los mercados y de diversificar los orígenes de sus ingresos. Menores ganancias en algún eslabón de la cadena pueden significar aumentos de los beneficios en otro eslabón controlado por la misma empresa. ${ }^{14}$

Las ganancias de estas empresas no dependen solamente de los precios de las materias primas o de los márgenes de comercialización derivados del transporte y almacenamiento; pueden provenir también de los beneficios de la producción y comercialización de muy diversos productos agroalimentarios o industriales. Otras fuentes importantes de ingreso pueden ubicarse en la especulación financiera en los mercados de derivados, en arbitrajes entre tasas de interés o diferentes divisas, o en la selección de países para la consolidación de las ganancias y el pago de impuestos.

Archer Daniels Midland (ADM). Fue fundada en 1902 en Estados Unidos. En 2013 realizó ventas por 89900 millones de dólares; en 2014 la suma fue algo menor, $81 \mathrm{mil} \mathrm{mi-}$ llones de dólares. Está presente en 75 países, pero tiene socios en 140 países. Comprende 10 segmentos de mercado: i) Alimentos, que incluye la producción de lectinas, harinas, proteínas, vitaminas y otros para la producción de cereales; productos para hornear; lácteos y carne; entre otros. ii) Productos para la alimentación y el cuidado del ganado. iii) Combustibles como etanol y biodiesel. iv) Productos industriales para diversas ramas productivas. v) Suplementos alimenticios. vi) Servicios al productor, como manejo de riesgos y otros. vii) Servicios logísticos. viii) Tecnología e in-

14 Braun, J. D. Burch y J. Clapa, El lado oscuro del comercio mundial de cereales. El impacto de las cuatro grandes comercializadoras sobre la agricultura mundial, Londres, oxfam International, 2012, p. 27. 
Cuadro 2

Características generales de las empresas ABCD (datos de 2014)

\begin{tabular}{ccccc}
\hline & ADM & BOUNGE & CARGILL & LOUIS DREYFUS \\
\hline País de origen & Estados Unidos & Países bajos & Estados Unidos & Francia \\
Año de fundación & 1902 & 1818 & 1865 & 1851 \\
Ventas Netas mmd & 81.0 & 57.2 & 134.9 & 64.7 \\
Beneficios Netos & 2.24 & 1.3 & 1.87 & 1.7 \\
mmd & 33000 & 35000 & 143000 & 34000 \\
Empleados & 75 & 40 & 67 & 55 \\
Países & & & \\
\hline
\end{tabular}

Fuente: elaboración propia con información de las páginas electrónicas de las empresas.

novación. ix) Servicios financieros. x) Comercialización de diversos productos bajo marcas propias. ${ }^{15}$

Bunge. Es la más antigua de las ABCD. Fue fundada originalmente en Países Bajos en 1818. En 2014 realizó ventas por 57160 millones de dólares; en 2013 había facturado 61350 millones de dólares. Está organizada en cuatro segmentos de negocios, aunque el de "Agronegocios" abarca diferentes actividades. i) Agronegocios: compra, transporta y vende semillas y granos; elabora y vende productos para la ganadería; ofrece servicios financieros y de manejo de riesgos. ii) Producción y venta de azúcar y etanol. iii) Producción de alimentos, como aceites, grasas, margarinas y mayonesa; así como harinas de trigo, maíz y arroz. iv) Producción y venta de fertilizantes de nitrógeno, fosfato y potasio. ${ }^{16}$

Cargill. Fundada en Estados Unidos en 1865, es la mayor compañía agrícola de Estados Unidos. En 2014 facturó 134900 millones de dólares (133900 millones en 2013). Es el segundo productor de vacuno de Estados Unidos, una de las mayores compañías de cacao del mundo y posee empresas dedicadas a con-

15 Página Web de la empresa disponible en www.adm. com

16 Página Web de la empresa, disponible en www. bunge.com vertir el maíz en biocarburantes, así como en alimentos para personas y en piensos. También vende fertilizantes e ingredientes para la industria farmacéutica. ${ }^{17}$

Louis Dreyfus. Se fundó en Francia en 1851. En 2014 realizó ventas por 64700 millones de dólares. Se dedica principalmente al procesamiento y comercialización de bienes de consumo agrícolas, petrolíferos y energéticos. Posee y administra buques transoceánicos, desarrolla y opera infraestructuras de telecomunicaciones, además de tener negocios inmobiliarios. $^{18}$

Las barreras de entrada al mercado de las $A B C D$ son muy elevadas, principalmente por la enorme escala de operación internacional y los grandes requerimientos de equipo de transporte y de infraestructura de almacenamiento y comercialización para productos perecederos y de baja densidad económica. En ocasiones los márgenes de ganancia son relativamente bajos, pero lo importante para estas empresas es mantener los elevados volúmenes de operación en la diversidad de líneas de actividad que desarrollan.

17 Página Web de la empresa, disponible en www.cargill. com

18 Página Web de la empresa, disponible en www.ldcom.com 
La logística de comercialización internacional de productos que exigen condiciones rigurosas para su manejo, almacenamiento y transporte, así como el cumplimiento de legislaciones para su internamiento en los diferentes países, implica grandes desafíos administrativos y de operación que las cuatro grandes empresas pueden enfrentar gracias a sus sistemas mundiales de acopio, transporte, almacenamiento y entrega. Las redes de contactos, vendedores o compradores, en los diversos países involucrados y su relación con la disponibilidad de la infraestructura específica requerida en cada caso, constituyen ventajas de las ABCD difícilmente asequibles para los eventuales competidores. Desde luego, la información de las condiciones de los mercados y el manejo de inventarios en muchos de ellos representan también importantes ventajas muy consolidadas.

Sin embargo, en los últimos años están surgiendo empresas competidoras, sobre todo en Asia, como las japonesas Mitsubishi y Marubeni, que principalmente operan comprando en el mercado mundial para el abastecimiento de la demanda de Japón, o el Grupo Charoen Pokphand, con sede en Bangkok, y Olam, con sede en Singapur. No obstante, simultáneamente se desarrolla un proceso, paralelo y en sentido contrario, de adquisiciones por parte de las ABCD de diversas empresas participantes en las cadenas agroalimentarias. ${ }^{19}$

La actividad de las ABCD se ha adecuado a los drásticos cambios en los mercados internacionales de alimentos originados en el presente siglo y a través de su amplia diversidad de actividades ha incidido en los mismos. En los últimos años, a pesar de la disminución de los

19 Braun, J. D. Burch y J. Clapa, El lado oscuro del comercio mundial de cereales. El impacto de las cuatro grandes comercializadoras sobre la agricultura mundial, Londres, oxfam International, 2012, p. 61.

\section{$2 S_{75 \% \text { del comercio }}^{\mathrm{ABCD} \text { controlan }}$ mundial de cereales. Además tienen una alta participación en el comercio mundial de soya, aceite de palma, algodón y diversas materias primas y productos elaborados}

precios de los alimentos desde 2014, cada una de las ABCD ha mantenido beneficios que superan los mil millones de dólares anuales (ver cuadro 2).

Las ABCD controlan 75\% del comercio mundial de cereales. Además tienen una alta participación en el comercio mundial de soya, aceite de palma, algodón y diversas materias primas y productos elaborados. ${ }^{20}$

Frecuentemente, los análisis de los mercados y los precios de los alimentos hacen referencia a variables nacionales, como la producción de cereales o granos en tal o cual país, la exportación desde tal otro, etc. Sin embargo, cuando se dice que Brasil es un gran exportador de soya debe considerarse que $60 \%$ de la producción de soya de ese país está financiado por Cargill, que Archer Daniels Midland es una de las principales procesadoras de soya en este país y que Bunge es el mayor productor,

20 Braun, J. D. Burch y J. Clapa, El lado oscuro del comercio mundial de cereales. El impacto de las cuatro grandes comercializadoras sobre la agricultura mundial, Londres, OXFAM International, 2012, p. 9. 
Cuadro 3

Evolución del volumen de inventarios de cereales, 2001-2016

\begin{tabular}{|c|c|c|c|c|c|c|c|c|}
\hline \multirow{3}{*}{ Periodo } & \multicolumn{2}{|c|}{ Cereales } & \multicolumn{2}{|r|}{ Arroz } & \multicolumn{2}{|r|}{ Trigo } & \multirow{2}{*}{\multicolumn{2}{|c|}{$\begin{array}{cc} & \text { Maíz } \\
\text { mundo } \quad \begin{array}{c}\text { principales } \\
\text { exportadores }\end{array}\end{array}$}} \\
\hline & mundo & $\begin{array}{c}\text { principales } \\
\text { exportadores }\end{array}$ & mundo & $\begin{array}{l}\text { principales } \\
\text { exportadores }\end{array}$ & mundo & $\begin{array}{l}\text { principales } \\
\text { exportadores }\end{array}$ & & \\
\hline & \multicolumn{8}{|c|}{ Porcentaje } \\
\hline $2001 / 02$ & 29.9 & 21.3 & 35.3 & 25.6 & 39.1 & 22.5 & 21.4 & 15.9 \\
\hline $2002 / 03$ & 25 & 16 & 29.2 & 15.6 & 34.4 & 19.2 & 17.3 & 13.1 \\
\hline $2003 / 04$ & 20.9 & 14.8 & 26.1 & 16.1 & 26.5 & 17.7 & 15.3 & 10.6 \\
\hline $2004 / 05$ & 23.2 & 17.3 & 24.2 & 13.5 & 28.5 & 20.9 & 19.4 & 17.4 \\
\hline $2005 / 06$ & 22.4 & 18.6 & 24.9 & 16.7 & 27.7 & 21.9 & 18 & 17.2 \\
\hline $2006 / 07$ & 19 & 14.6 & 24.2 & 16.6 & 23.3 & 14.9 & 14.5 & 12.1 \\
\hline $2007 / 08$ & 18.5 & 15.2 & 25.7 & 18.9 & 20 & 14 & 14.7 & 12.6 \\
\hline $2008 / 09$ & 22.2 & 19.5 & 29.3 & 23.5 & 24.7 & 18.8 & 17.9 & 16.3 \\
\hline $2009 / 10$ & 24.5 & 20 & 29.9 & 21.6 & 30.3 & 22.5 & 19.1 & 16 \\
\hline $2010 / 11$ & 23.4 & 17.8 & 31.1 & 20.7 & 28.3 & 21.4 & 17.2 & 11.1 \\
\hline $2011 / 12$ & 24.3 & 18.1 & 34.2 & 25 & 28.8 & 18.2 & 17.6 & 11.1 \\
\hline $2012 / 13$ & 22.5 & 17 & 36.1 & 28.6 & 25.2 & 13.7 & 15.6 & 8.6 \\
\hline $2013 / 14$ & 24.2 & 17.3 & 36.4 & 26.9 & 26.2 & 13.7 & 18.3 & 11.2 \\
\hline $2014 / 15$ & 25.6 & 17.7 & 35 & 23.6 & 27.9 & 15.5 & 20.7 & 13.9 \\
\hline $2015 / 16$ & 25 & 16.4 & 32.6 & 18.7 & 28.3 & 16.8 & 20.5 & 13.6 \\
\hline
\end{tabular}

Fuente: elaboración propia con datos de FAO GIEWS, 2015.

procesador y exportador de soya en América del Sur y el mayor productor de aceite de soya en el mundo.

Cuando se plantean los progresos en la producción de cereales de Argentina debe recordarse que Bunge es la mayor comercializadora de cereales en América del Sur.

Cuando se señala que Estados Unidos es el primer productor de etanol en el mundo, debe tenerse en cuenta que Archer Daniels Midland es el segundo mayor productor de etanol en ese país, así como un importante productor de biodiesel en el mercado europeo. Por su parte, Louis Dreyfus posee la mayor refinería de diesel en Estados Unidos. ${ }^{21}$

21 Braun, J. D. Burch y J. Clapa, El lado oscuro del comercio mundial de cereales. El impacto de las cuatro grandes comercializadoras sobre la agricultura mundial, Lon-
Cuando se habla de la participación de los países africanos en la producción mundial de cacao, debe tenerse presente que Archer Daniels Midland es la mayor procesadora de semillas de cacao, a partir del abastecimiento proveniente de Camerún, Costa de Marfil, Ghana e indonesia. Algo semejante habría de considerarse con la participación de Cargill respecto del aceite de palma de Indonesia, algodón en Uzbequistán o cacao en Ghana. ${ }^{22}$

Sin duda, la economía política involucrada en los mercados agroalimentarios y en el comportamiento de los precios de alimentos cam-

dres, OXFAM International, 2012, p. 10.

22 Braun, J. D. Burch y J. Clapa, El lado oscuro del comercio mundial de cereales. El impacto de las cuatro grandes comercializadoras sobre la agricultura mundial, Londres, OXFAM International, 2012, p. 10. 
Luis Gómez Oliver | Rosario Granados Sánchez |

Las cuatro grandes empresas comercializadoras y los precios internacionales de los alimentos

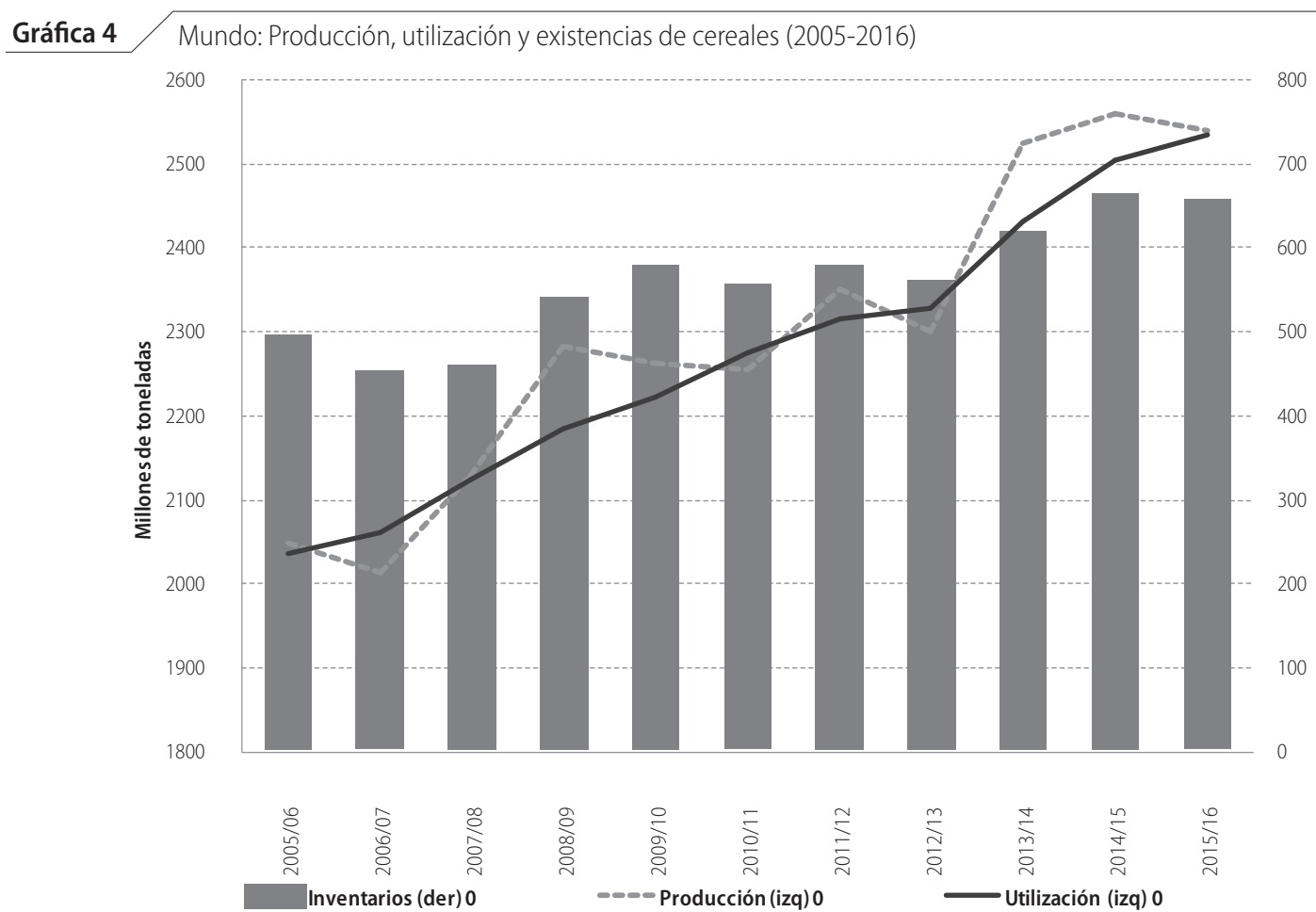

Fuente: elaboración propia con datos de FAO GIEWs, 2015.

bia sustantivamente cuando en lugar de considerar variables que reflejan intereses nacionales que implícitamente se suponen válidos para el conjunto de la población, se identifican los agentes privados y sus intereses, particularmente cuando se trata de agentes tan poderosos e influyentes como las ABCD.

Una variable crucial en los márgenes de mercado en el comercio mundial es el manejo de los inventarios. Las existencias mundiales de cereales que al inicio de la década eran casi $30 \%$ de la utilización anual, llegaron a un mínimo de menos de 19\% en los ciclos 2006/07 y $2007 / 08$. En los principales países exportadores los inventarios estuvieron por debajo de $15 \%$ de los requerimientos anuales.

En el bienio señalado los inventarios de trigo llegaron a ser solamente $20 \%$ de la utilización anual, cuando que normalmente alcanzaban cerca de $30 \%$ o más; en los principales países exportadores estuvieron por debajo de 15\%. Las existencias mundiales de maíz también cayeron significativamente, a menos de $15 \%$ y en los principales países exportadores a menos de $13 \%$. Aunque en arroz no hubo una disminución tan marcada en las existencias, las compras de pánico en varios países asiáticos dispararon el precio internacional, incluso más que en los otros cereales básicos.

El alto grado de participación de las $\mathrm{ABCD}$ en la comercialización mundial de granos, así como sus múltiples actividades a lo largo de las cadenas de producción-consumo, les da un enorme poder de mercado. La información privilegiada sobre las condiciones de producción e inventarios existentes en los diversos países y su capacidad para operar en casi todos ellos en diferentes eslabones de la cadena les permite arbitrar sobre márgenes de ganancia en diferentes actividades en distintas regiones. Por 
ejemplo, cuando la sequía en Estados Unidos y otros factores llevaron los inventarios de maíz a niveles extremadamente bajos, una gran empresa comercializadora y, a la vez, importante productora de carne podía beneficiarse de los altos precios del grano vendiéndolo externamente, o bien de los altos precios de la carne si asumía los costos del precio alto del cereal. Las opciones de este tipo de arbitrajes a lo largo de las diferentes cadenas y en las diferentes regiones son innumerables.

Además, siendo tan reducido el número de empresas y tan elevado su grado de participación en el mercado, no puede desdeñarse el riesgo de concertación en las intervenciones en los mercados, lo que podría entrañar incluso riesgos de colusión para favorecer sus intereses.

En la última década las ventas de las ABCD se duplicaron sobradamente, a partir de la participación en los mercados agroalimentarios internacionales en 2005, la cual ya era muy elevada. Hasta 2011 el índice de ventas siguió aproximadamente la evolución del índice de precios de los alimentos; pero cuando éstos comenzaron a bajar, las ventas de las $\mathrm{ABCD}$, mantuvieron el nivel alcanzado.

\section{Conclusión}

Las ABCD realizan eficazmente una labor sumamente compleja e importante, al organizar toda la logística y llevar a cabo los movimientos físicos de los alimentos, conectando, en tiempo y espacio, las regiones productoras con las poblaciones consumidoras. Asimismo, participan con gran eficiencia en la integración de las cadenas de producciónconsumo de los alimentos, tanto en los procesos de elaboración de productos intermedios y finales como en los aspectos institucionales para la organización del comercio en las diversas etapas y los numerosos mercados de destino final. Estas funciones son cruciales para el abastecimiento mundial de alimentos, así como para la operación de los mercados agroalimentarios. Los aportes de estas empresas en la eficiencia y la generalización de tecnologías para mejorar de la producción y el comercio de los alimentos son también muy relevantes.

Sin embargo, la propia importancia de estas cuatro empresas en un área tan extremadamente sensible como los sistemas agroalimentarios mundiales, así como su amplia participación en los mercados y la concentración de poder que representa su reducido número, que les permite relacionarse desde posiciones ventajosas no solo con otros agentes privados, sino, incluso, con poderes públicos, hace evidente la necesidad de reducir la opacidad de su operación, logrando mayor transparencia en la información y favoreciendo la competencia. ?

Cuadro 4

Ventas de las empresas $A B C D$ a precios nominales (mmd)

\begin{tabular}{|c|c|c|c|c|c|c|c|c|c|c|}
\hline & 2005 & 2006 & 2007 & 2008 & 2009 & 2010 & 2011 & 2012 & 2013 & 2014 \\
\hline Cargill & $\$ 69.93$ & $\$ 73.51$ & $\$ 86.19$ & $\$ 101.90$ & $\$ 96.98$ & $\$ 101.31$ & $\$ 119.47$ & $\$ 133.86$ & $\$ 136.65$ & $\$ 134.87$ \\
\hline BUNGE & $\$ 24.38$ & $\$ 26.27$ & $\$ 37.84$ & $\$ 52.57$ & $\$ 41.93$ & $\$ 43.95$ & $\$ 56.10$ & $\$ 60.99$ & $\$ 61.35$ & $\$ 57.16$ \\
\hline ADM & $\$ 35.83$ & $\$ 39.09$ & $\$ 52.92$ & $\$ 78.33$ & $\$ 62.21$ & $\$ 68.58$ & $\$ 81.60$ & $\$ 90.56$ & $\$ 89.80$ & $\$ 81.20$ \\
\hline Louis Dreyfus & ND & ND & ND & ND & ND & ND & $\$ 57.70$ & $\$ 57.10$ & $\$ 63.60$ & $\$ 64.70$ \\
\hline TOTAL & $\$ 130.14$ & $\$ 138.87$ & $\$ 176.95$ & $\$ 232.80$ & $\$ 201.11$ & $\$ 213.84$ & $\$ 314.87$ & 342.51 & $\$ 351.40$ & $\$ 337.93$ \\
\hline
\end{tabular}

Fuente: elaboración propia con datos de las empresas. 


\section{Luis Gómez Oliver | Rosario Granados Sánchez |}

Las cuatro grandes empresas comercializadoras y los precios internacionales de los alimentos

Gráfica 5 Índice de ventas de las empresas ABCD e Índice de precios de los alimentos a precios nominales, 2005-2014

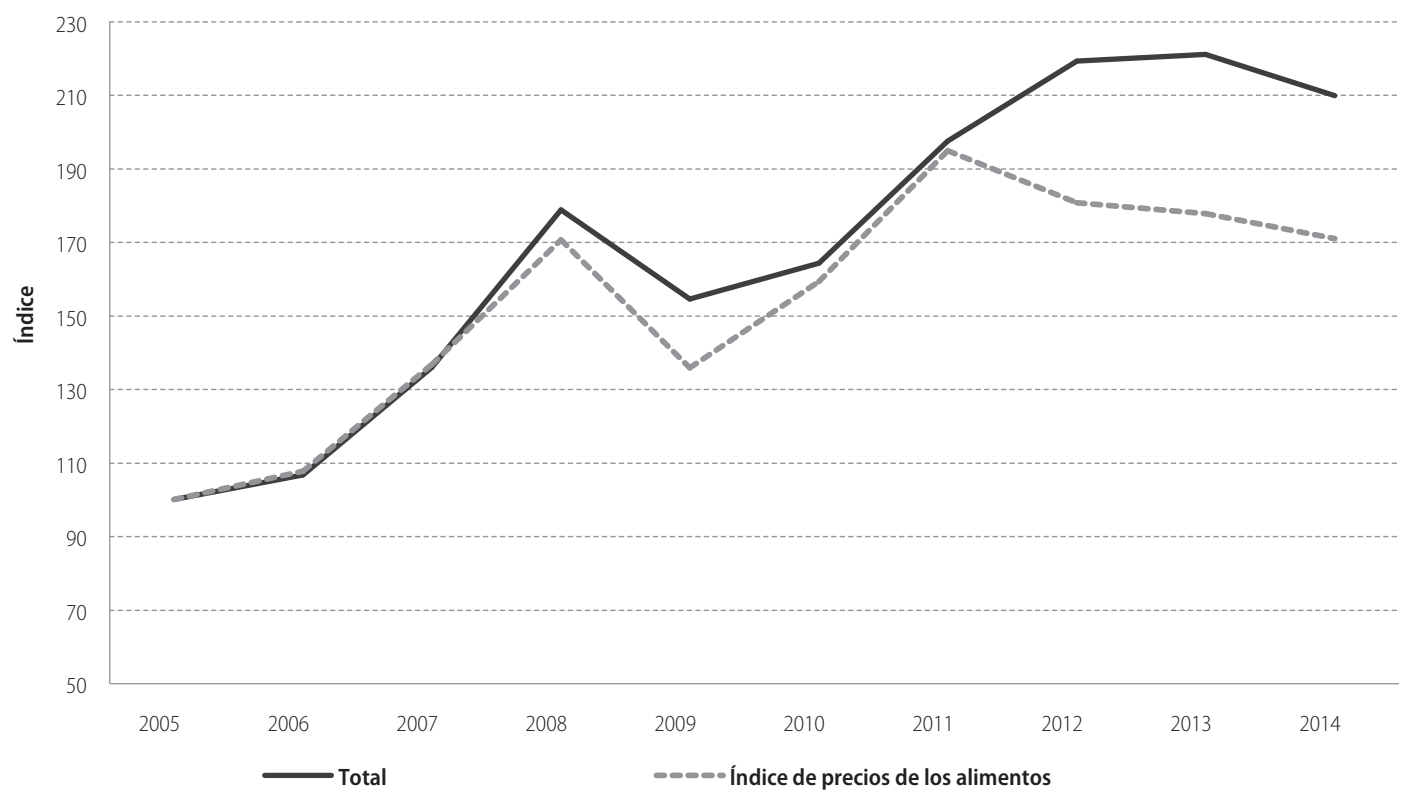

Fuente: elaboración propia con datos de FAOSTAT, 2015 y reportes financieros de las empresas.

\section{Bibliografía}

Burns, A. and E. Riordan, Global Economic Prospects, Volume 3, Washington D.C., World Bank, 2011.

Conferencia de Alto Nivel sobre la Seguridad Alimentaria Mundial: Los Desafios del Cambio Climático y la Bioenergía, Organización de las Naciones Unidas para la Agricultura y la Alimentación, FAO, Roma, 2008.

El estado de los mercados de los productos básicos agrícolas - 2006, Organización de las Naciones Unidas para la Agricultura y la Alimentación, FAO, Roma, 2007.

Food and Fuel Prices - Recent Developments, Macroeconomic Impact, and Policy Responses, International Monetary Fund, IMF, Washington, 2008.

Food Outlook, Global MarketAnalysis, Organización de las Naciones Unidas para la Agricultura y la Alimentación, FAO, Roma, 2008.

Food Price Watch, Washington D.C., World Bank, 2011.
Gómez Oliver, Luis. Conferencia magistral: Desarrollo del sector agropecuario en el marco de la sustentabilidad y la seguridad alimentaria, IIEC de la UNAM, México, 2013,

High Food Prices: The What, Who, and How of Proposed Policy Actions, Policy Brief, May 2008, International Food Policy Research Institute, IFPRI, Washington, 2008.

Perspectivas alimentaria. Análisis del mercado mundial, Roma, Organización de las Naciones Unidas para la Agricultura y la Alimentación, FAO, 2008.

Tendencias y desafios de la agricultura, los montes y la pesca en América Latina y el Caribe - 2006, Organización de las Naciones Unidas para la Agricultura y la Alimentación, FAO, Oficina Regional para América Latina y el Caribe, Santiago, 2006.

Trostle Ronald, Global Agriculture Supply and Demand: Factors Contributing to the Recent Increase in Food Commodity Prices, United States Department of Agriculture, 2008. 